\title{
Dietary vitamin $D$ and calcium intake of morbidly obese pregnant women
}

\author{
M. S. Charnley ${ }^{1}$, A. F. Hackett ${ }^{1}$ and J. C. Abayomi ${ }^{1,2}$ \\ ${ }^{1}$ Faculty of Education, Community and Leisure, Liverpool John Moores University, Barkhill Road, Liverpool L17 6BD and \\ ${ }^{2}$ Liverpool Women's Hospital, Crown Street, Liverpool L8 7SS
}

Vitamin D is essential for Ca homoeostasis and bone health, and also plays a much wider role in general health and disease prevention ${ }^{(1)}$. No dietary reference values (DRV) are set for adults in the UK who live a normal lifestyle, however, plasma concentrations are dependent on the amount of exposure to UV light during the summer months, which vary depending on the amount of time spent outdoors, inclement weather, mobility and cultural influences. For individuals who have limited exposure to UV, a reference nutrient intake (RNI) of $10 \mu \mathrm{g} / \mathrm{d}$ has been agreed; this includes all pregnant and lactating women. There are limited dietary sources of vitamin D, which include fatty fish, eggs and fortified foods such as margarine and some breakfast cereals ${ }^{(2)}$. Prolonged deficiency of vitamin D has deleterious consequences for bone health and fetal bone development; studies have found poor maternal vitamin D status is linked to reduced bone mass in the offspring at age $9^{(3)}$. The risks are compounded further in obese pregnant women as studies have shown that obesity is linked to vitamin D deficiency ${ }^{(4)}$. It is hypothesised that deficiencies in vitamin D give rise to metabolic syndrome and its associated diseases such as type 2 diabetes mellitus (T2DM) and CVD, due to seasonal variation of glycaemic control ${ }^{(5)}$. An inverse relationship between plasma levels of 25-(OH) D and measurements of glycaemia and presence of T2DM has been observed in a number of studies ${ }^{(5)}$. The aim of the study was to calculate the dietary intake of vitamin D and Ca relative to RNI and lower RNI of obese pregnant women with a BMI $\geq 35 \mathrm{~kg} / \mathrm{m}^{2}$. Women were recruited from an antenatal clinic and asked to complete 3-d food diaries during each trimester of pregnancy. Data regarding food portion size were verified using a food atlas ${ }^{(6)}$ and the diaries were then analysed using Microdiet ${ }^{\mathrm{TM}}$.

Vitamin D and Ca intake over three trimesters

\begin{tabular}{|c|c|c|c|c|c|c|c|c|c|}
\hline & \multicolumn{5}{|c|}{ Vitamin D } & \multicolumn{2}{|c|}{$\mathrm{Ca}$} & \multicolumn{2}{|c|}{ Maternal wt in $\mathrm{kg}$} \\
\hline & $\begin{array}{l}\text { Mean } \\
(\mu \mathrm{g} / \mathrm{d})\end{array}$ & SD & $\begin{array}{c}\text { RNI\% } \\
(10 \mu \mathrm{g} / \mathrm{d})\end{array}$ & $\begin{array}{l}\text { Mean } \\
(\mathrm{mg} / \mathrm{d})\end{array}$ & SD & $\begin{array}{c}\text { RNI \% } \\
(700 \mathrm{mg} / \mathrm{d})\end{array}$ & $\begin{array}{c}\text { LRNI\% } \\
(400 \mathrm{mg} / \mathrm{d})\end{array}$ & Mean & SD \\
\hline Trimester 1 & 2.6 & 2.5 & 3 & 875 & 334.4 & 65 & 96 & 110.1 & 15.5 \\
\hline Trimester 2 & 2.3 & 2 & 2 & 949 & 356.8 & 72 & 98 & 114.9 & 14.8 \\
\hline Trimester 3 & 2.6 & 2.5 & 1 & 994 & 423.6 & 78 & 95 & 112.3 & 12 \\
\hline
\end{tabular}

Data were collected for 140 pregnant women with a BMI $\geq 35 \mathrm{~kg} / \mathrm{m}^{2}$, with a mean booking-in weight of $110 \mathrm{~kg}$ (SD 15.5 ). The results table shows that dietary intake of vitamin D is poor with only $3 \%$ of women achieving the RNI in trimester 1 and $1 \%$ in trimester 3 , mean intake was not more than $2.6 \mu \mathrm{g} / \mathrm{d}$ (SD 2.5) in any trimester. Mean Ca intake ranged from $875 \mathrm{mg} / \mathrm{d}$ (SD 334.4 ) in trimester 1 to $994 \mathrm{mg} / \mathrm{d}$ (SD 423.6) in trimester 3 suggesting that most women are achieving RNI, however, there is wide variation around the mean with minimum intake as little as $159 \mathrm{mg} / \mathrm{d}$ in trimester 2; approximately $4 \%$ of women on average did not achieve LRNI. It appears prudent to recommend supplementation of vitamin D for all pregnant women but particularly for women with a BMI $\geq 35 \mathrm{~kg} / \mathrm{m}^{2}$.

1. Hollis BW \& Wagner CL (2006) Nutritional vitamin D status during pregnancy: reasons for concern. CMAJ 174, 1287-1290.

2. COMA (1991) Dietary Reference Values for Food, Energy and Nutrients for the UK. HMSO: London.

3. Javaid MK, Crozier SR, Harvey NC et al. (2006) Maternal vitamin D status during pregnancy and childhood bone mass at age 9: a longitudinal study. Lancet 367, 36-43.

4. Wortsman J, Matsuoka L Y, Chen T C et al. (2000) Decreased bioavailability of vitamin D in obesity. Am J Clin Nutr 72, 690-693.

5. Meerza D, Naseem I \& Ahmed J (2010) Can vitamin D be a potential treatment for type 2 diabetes mellitus. Diabetes Metab Syndr: Clin Res Rev 4, $245-248$.

6. Nelson M, Atkinson M \& Meyer J (2002) A photographic atlas of food portion sizes FSA. 